\title{
Synthesis and characterization of porous cytocompatible scaffolds from polyvinyl alcohol-chitosan
}

\author{
MAHDI ZOLGHADRI ${ }^{1}$, SAEED SABER-SAMANDARI ${ }^{1, *}$, SARA AHMADI ${ }^{1}$ \\ and KADHIM ALAMARA ${ }^{2}$ \\ ${ }^{1}$ New Technologies Research Center, Amirkabir University of Technology, Tehran 1591634653, Iran \\ ${ }^{2}$ Sustainable and Renewable Energy Engineering (SREE), University of Sharjah, Sharjah 2727227272, UAE \\ *Author for correspondence (saeedss@aut.ac.ir)
}

MS received 22 January 2018; accepted 18 June 2018; published online 2 February 2019

\begin{abstract}
In this study, novel porous cytocompatible scaffolds with a 3D nanocomposite structure were synthesized by using nanoclay particles embedded into a biopolymer blend composed of polyvinyl alcohol (PVA) and chitosan (CS). According to the results, the Fourier transform infrared spectrum confirmed the presence of nanoclay, PVA and CS in the scaffold structure. X-ray diffraction outcomes showed the enhancement of crystalline zone in the synthesized 3D scaffolds by increasing the nanoclay content. Scanning electron microscopy (SEM) images revealed the highly porous interconnected microstructure of the scaffolds. Also, the energy-dispersive X-ray spectra verified the presence of nanoclay, PVA and CS in the sample with the highest nanoclay content. According to mechanical properties and porosity of the synthesized 3D scaffolds, compressive strength (i.e., $3.5 \pm 0.2 \mathrm{MPa})$, elastic modulus $(1.42 \pm 0.02 \mathrm{GPa}$ ) and porosity $(75-82 \%)$ of the sample with the highest nanoclay content was in the range of mechanical properties and porosity of a natural trabecular bone tissue. The swelling of samples in a phosphate-buffered saline solution was less than the swelling in water. In addition, increasing the content of nanoclay decreases the percentage of swelling. Outcomes of cell culture experiments confirmed that the synthesized 3D scaffolds were not toxic and the cell attachment SEM images showed a sufficient attachment of the cell to the interconnected porous structure of the sample. Results suggest that the synthesized 3D scaffold in this study possesses proper microstructure properties and no cytotoxicity to be replaced with natural bone tissues.
\end{abstract}

Keywords. Bone tissue engineering; nanoclay particles; polyvinyl alcohol; chitosan.

\section{Introduction}

In orthopaedic surgery, repairing of bone tissue is a major problem due to a number of bone tissue disorders, such as infection, tumours and abnormalities [1]. Common treatment methods of these bone diseases are categorized in three techniques including autografts, allografts and xenografts. Among all of these methods, autografts have been shown to be the most suitable technique for bone regeneration. In this method, surgeons remove a healthy bone tissue from another donor site. Two major obstacles in this technique are the high possibility of donor site morbidity, and also difficulty in constructing a proper shaped tissue using the dissected one [2,3]. Furthermore, in allografting and xenografting techniques, there is a feasibility of pathogen transfer or immune reaction $[4,5]$. To overcome all the disadvantages of the common treatments of bone disorders, researchers have been developed an alternative method which is fabrication of synthesized 3D bone graft scaffolds by employing a composition of synthetic polymers (i.e., polyvinyl alcohol (PVA), polycaprolactone (PCL) and poly(lactic-co-glycolic acid) (PLGA)) [6-8], natural polymers (i.e., chitosan (CS), gelatin and cellulose) [9-11] and reinforcement particles (i.e., ceramics)
$[12,13]$. These synthesized 3D scaffolds have shown desirable micro- and macro-structural properties in comparison with the natural bone tissues [13-16].

PVA is a synthetic polymer with hydrophilic properties and semi-crystalline structure. This polymer contains abundant number of hydroxyl functional groups which are capable of easily bonding with surrounded free water molecules. PVA has shown desirable biocompatibility and physical properties. Hence, this polymer has been widely employed in biomedical and pharmaceutical applications $[8,17]$. Recently, fabrication of physically cross-linked PVA hydrogels has been attracted a number of researches due to its excellent mechanical properties and biocompatibility $[18,19]$. In addition, blending of polymeric materials has been always known as an efficient technique to enhance their properties. Blending of PVA in order to enhance its properties has been reported by using some polymers such as cassava starch, hyaluronic acid, polyurethane and CS [20-22]. CS, that is deacetylated form of chitin, consists of $(1,4)$-linked 2 -amino-deoxy- $\beta$-D-glucan which is a linear polysaccharide. The commercial resource of CS is shrimp and crap shell chitin (an $N$-acetylglucosamine polymer). CS has unique properties including remarkable 
biocompatibility, biodegradability, non-toxicity, antibacterial activity, mucoadhesivity, high molecular weight, viscosity, crystallinity and ability to create intermolecular hydrogen bonds. Hence, CS is widely utilized in biomedical applications such as tissue engineering, wound healing and dressing, developing drug delivery systems and fabrication of separation membranes $[23,24]$. The composition of PVA/CS possesses biocompatibility, antibacterial and anti-inflammatory $[22,25]$. In the last few decades, researchers have improved the properties of blended polymeric matrixes by incorporation of nanoparticles $[8,9,26]$. Results revealed that even addition of up to $5 \mathrm{wt} \%$ of nanoparticles increases the mechanical and thermal properties of the nanocomposite in comparison with the conventional composites. Nanoclay particles or montmorillonite (MMT) is a low cost and naturally available layered silicate that is commonly employed to improve mechanical strength of polymeric films [27]. Some researchers have been studied the composition of the PVA/CS polymeric matrix incorporated with nanoclay particles [28-30], however, the mechanical and biocompatibility of this nanocomposite as a 3D synthesized scaffold with potential of in vivo applications has not been considered.

In this study, nanoclay particles were incorporated into the PVA/CS 3D scaffolds to improve the mechanical properties and bioactivity of the nanocomposite to be used for bone tissue replacement applications. To achieve this goal, PVA/CS/nanoclay synthesized 3D scaffolds were fabricated by the freeze-drying technique. The microstructure and morphology of the synthesized 3D scaffold were determined by Fourier transform infrared spectroscopy (FTIR), X-ray diffraction analyses (XRD), scanning electron microscopy (SEM) and energy-dispersive X-ray spectroscopy (EDX). To compare the macrostructure of samples and their mechanical properties with natural bone tissues, compressive strength and elastic modulus of the scaffolds were measured by running a tensile test. The biostability of the synthesized 3D scaffold was examined by carrying out the swelling test in both distilled water and phosphate-buffered saline (PBS) solution. The 3-[4,5-dimethylthiazol-2-yl]-2,5-diphenyltetrazolium bromide (MTT) assay by using L929 cells was employed to determine the cytotoxicity and biocompatibility of the samples. The SEM images after cell culturing experiment of the structure of synthesized 3D scaffold was taken to show the attachment of L929 cells to the samples.

\section{Materials and methods}

\subsection{Materials}

PVA was commercially purchased with the following characteristics: $\mathrm{MW}=18,300$ and $1.3 \mathrm{~g} \mathrm{~cm}^{-3}$ density. Medium molecular weight CS (Aldrich) with 75-85\% deacetylation and potassium persulphate $(\mathrm{BDH})$ as an initiator was used to synthesize the nanocomposite scaffold. Acetic acid (37\%) was used as a solvent for CS. Nanoclay powder $(<100 \mathrm{~nm}$ particle size, $\geq 97 \%)$ was supplied by Southern Clay Products. Disodium hydrogen phosphate, sodium chloride, potassium chloride and potassium dihydrogen phosphate were purchased from Aldrich and were used for preparation of PBS solution. The PBS solution was prepared by dissolving four salts $\mathrm{NaCl}(8 \mathrm{~g}), \mathrm{KCl}(0.2 \mathrm{~g}), \mathrm{Na}_{2} \mathrm{HPO}_{4}$ $(1.44 \mathrm{~g})$ and $\mathrm{KH}_{2} \mathrm{PO}_{4}(0.24 \mathrm{~g})$ in distilled water $(800 \mathrm{ml})$. After adjusting the $\mathrm{pH}$ of the solution to 7.4 with $\mathrm{HCl}$ $\left(1 \mathrm{~mol} \mathrm{l}^{-1}\right)$, the total volume of the solution reached 1 litre.

\subsection{Synthesis of 3D scaffolds}

A PVA solution of $5 \mathrm{wt} \%$ was prepared by mixing PVA in double distilled water followed by heating up to $90^{\circ} \mathrm{C}$ for $2 \mathrm{~h}$, under continuous mechanical stirring, to obtain a clear solution. A $5 \mathrm{wt} \% \mathrm{CS}$ solution was prepared by dissolving $\mathrm{CS}$ in $1 \%$ acetic acid solution at ambient temperature by stirring it overnight. The mixed solutions of PVA and CS mentioned above were stirred for $60 \mathrm{~min}$ at ambient temperature. The nanoclay powder was first dispersed in a $1 \%$ acetic acid solution by stirring it at room temperature for 12 $\mathrm{h}$, followed by ultra-sonication for $10 \mathrm{~min}$. The dispersion was added into the PVA/CS solution mentioned above, the resulted PVA/CS/clay dispersion being further stirred for $5 \mathrm{~h}$, followed by ultra-sonication for $10 \mathrm{~min}$ with different weight ratios of PVA/CS/clay that are tabulated in table 1. The formed mixtures of PVA/CS/clay were casted. Repeatedly, three cycles of freezing and thawing were performed by keeping the solutions of the blends at $-20^{\circ} \mathrm{C}$ for $12 \mathrm{~h}$ and then maintaining them at room temperature for the same time interval to complete one cycle. Following this step, the obtained well-dispersed slurries were poured into a polytetrafluoroethylene (PTFE) mould with a height of $20 \mathrm{~mm}$ and a diameter of $10 \mathrm{~mm}$. The prepared solutions were transferred into a freeze-dryer (FD-10, Pishtaz Engineering Co., Iran) then freezed up to

Table 1. Composition, mechanical properties, average pore size and porosity percentage of the synthesized 3D scaffolds.

\begin{tabular}{|c|c|c|c|c|c|c|c|}
\hline $\begin{array}{l}\text { 3D nanocomposite } \\
\text { scaffold identity }\end{array}$ & $\mathrm{CS}(\mathrm{g})$ & PVA (g) & Nanoclay (g) & $\begin{array}{l}\text { Elastic modulus } \\
\quad(\mathrm{GPa})\end{array}$ & $\begin{array}{c}\text { Compressive } \\
\text { strength (MPa) }\end{array}$ & Pore size $(\mu \mathrm{m})$ & Porosity (\%) \\
\hline $\mathrm{CO}$ & 0.4 & 0.2 & 0.0 & $0.75 \pm 0.02$ & $0.8 \pm 0.1$ & $130-140$ & $68-70$ \\
\hline $\mathrm{C} 1$ & 0.4 & 0.2 & 0.2 & $0.8 \pm 0.03$ & $1.4 \pm 0.1$ & $120-125$ & $76-83$ \\
\hline $\mathrm{C} 2$ & 0.4 & 0.2 & 0.3 & $1.2 \pm 0.01$ & $1.8 \pm 0.3$ & $115-120$ & $80-87$ \\
\hline $\mathrm{C} 3$ & 0.4 & 0.2 & 0.4 & $1.42 \pm 0.02$ & $3.5 \pm 0.2$ & 95-113 & $75-82$ \\
\hline
\end{tabular}


$-56^{\circ} \mathrm{C}$ (vacuum $6.2 \mathrm{mbar}$ ) for $8 \mathrm{~h}$ and then warmed to $-5^{\circ} \mathrm{C}$ ( $1.4 \mathrm{mbar})$ for $6 \mathrm{~h}$ and to $24^{\circ} \mathrm{C}(0.98 \mathrm{mbar})$ for 2 days in the main drying phase for 48 days.

\subsection{Synthesized 3D scaffold characterization}

To confirm the synthesis of PVA/CS/nanoclay 3D scaffolds, an FTIR spectrometer (Perkin-Elmer 8700, Japan) was employed to analyse the sample powder in a wavelength range of $500-4000 \mathrm{~cm}^{-1}$. An X-ray diffractometer (EQuiox 300 , France) was used with $\mathrm{Cu}-\mathrm{K} \alpha$ radiation $(1.54 \AA)$ in the range of $0-70^{\circ}$ of $2 \theta$. A current of $30 \mathrm{~mA}$ and voltage of $40 \mathrm{kV}$ were applied during running the XRD test. The morphological characteristics of 3D scaffolds were investigated by utilizing a SEM instrument (Tescan Vega 3 LMU with Bruker Quantax EDS, Czech Republic). SEM-EDX analyses were used to study the chemical composition of the samples. SANTAM compression test instrument (ASTM D5024-95, Iran) with a $0.5 \mathrm{~mm} \mathrm{~min} \mathrm{~min}^{-1}$ loading rate was employed to carry out the mechanical properties of 3D scaffolds. Samples were cut into $5 \mathrm{~mm}$ diameter and $10 \mathrm{~mm}$ height. Elastic modulus and compressive strength of the synthesized 3D scaffolds were calculated from the stress-strain curve.

\subsection{Synthesized 3D scaffold porosity and pore size determination}

A liquid displacement technique was employed to measure the apparent porosity of synthesized 3D scaffolds [31]. According to this method, $0.5 \mathrm{~g}$ of sample was immersed in distilled water and kept in the water container until all inner pores of the sample were loaded with water. Afterwards, the water loaded scaffold was removed and the volume of remaining water in the container was measured. The following equation was used to calculate the porosity percentage of the synthesized 3D scaffolds:

$$
\text { Porosity }(\%)=\left[\left(V_{1}-V_{3}\right) /\left(V_{2}-V_{3}\right)\right] \times 100
$$

Here, $V_{1}$ represents the initial volume of water in the container before placing the sample, $V_{2}$ is the volume of water while placing the sample and finally $V_{3}$ represents the volume of water in the container after removing the water-loaded sample.

The pore size of the synthesized 3D scaffolds was measured by using Image J software SEM in 10 different cross-sectional regions in their SEM micrographs. Approximately 50 pores were investigated and the average of them was reported.

\subsection{Synthesized 3D scaffold swelling behaviour}

In terms of scaffold fabrication for in vivo tissue engineering applications, study of the structural stability and more importantly the swelling behaviour of the synthesized scaffolds are critical [24]. Both distilled water and PBS solution were utilized to study the stability and swelling behaviour of the synthesized 3D scaffolds. The PBS solution was prepared by dissolving four salts including $8 \mathrm{~g}$ of $\mathrm{NaCl}$, $0.2 \mathrm{~g}$ of $\mathrm{KCl}, 1.44 \mathrm{~g}$ of $\mathrm{Na}_{2} \mathrm{HPO}_{4}$ and $0.24 \mathrm{~g}$ of $\mathrm{KH}_{2} \mathrm{PO}_{4}$ in $800 \mathrm{ml}$ of distilled water. The $\mathrm{pH}$ of the solution was adjusted to 7.4 by adding $\mathrm{HCl}\left(1 \mathrm{~mol} 1^{-1}\right)$.

The swelling measurement experiment was carried out by immersing a $0.5 \mathrm{~g}$ piece of sample in $50 \mathrm{ml}$ of distilled water or PBS solution. Loading of water and PBS began and continued until reaching the equilibrium state after specific time period. The equilibrium state is achieved when the swelling percentage of the sample does not show large differences by increasing time. The following equation was used to calculate the swelling percentage of synthesized 3D scaffolds:

$$
\text { Swelling }(\%)=\left[\left(W_{\mathrm{s}}-W_{\mathrm{d}}\right) / W_{\mathrm{d}}\right] \times 100
$$

Here, $W_{\mathrm{s}}$ represents the weight of swollen sample while $W_{\mathrm{d}}$ is the weight of dried one.

\subsection{Synthesized 3D scaffold cytotoxicity evaluation}

To perform the cytotoxicity experiments, the human osteoblast cells (L929) were provided from the National Cell Bank of Iran (NCBI). The Roswell Park Memorial Institute (RPMI) cell culture medium (Gibco, USA) by addition of $10 \%(\mathrm{v} / \mathrm{v})$ of foetal bovine serum (FBS, Gibco, USA), $100 \mathrm{U} \mathrm{m}^{-1}$ of penicillin and $100 \mathrm{\mu g} \mathrm{ml}^{-1}$ of streptomycin were employed to culture L929 cells. The cell culture platform was exposed to $5 \%$ of $\mathrm{CO}_{2}$ gas while incubating at $37^{\circ} \mathrm{C}$. Also, the cell culture environment was humidified during the experiment.

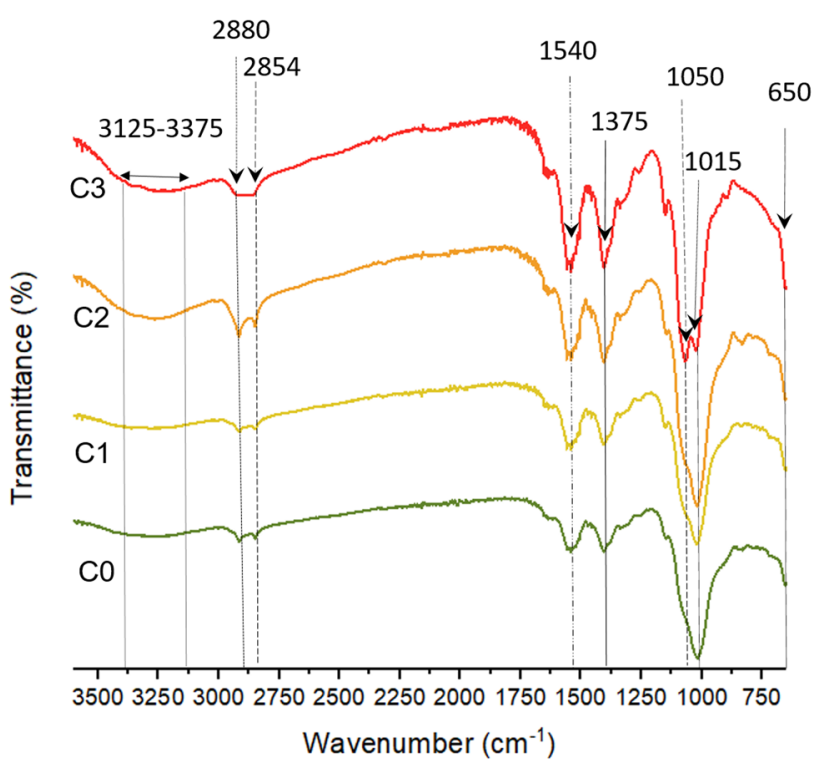

Figure 1. FTIR spectra of the synthesized 3D scaffolds (C0-C3) in the range of $625-3625 \mathrm{~cm}^{-1}$ which were determined by using an FTIR spectrometer. 
The MTT assay was used to investigate the biocompatibility of the synthesized 3D scaffolds in the powder form with different concentrations. A 24-walled microtitre plate (Nunc, Denmark) was employed to culture L929 cells with $2-3 \times 10^{4}$ cells per wall density. The cell culture medium was removed after $4-5 \mathrm{~h}$ and the plate was put into $90 \mu 1$ of sample powder extracts dissolved in $10 \mu \mathrm{l}$ of FBS. After $24 \mathrm{~h}$, the medium was completely removed and the cell culture plates were rinsed with PBS solution for $30 \mathrm{~s}$. The cell fixation process was carried out using $1.5 \%$ of glutaraldehyde. After keeping the cell-cultured plates at room temperature for $1 \mathrm{~h}$, glutaraldehyde was removed. The solutions of distilled

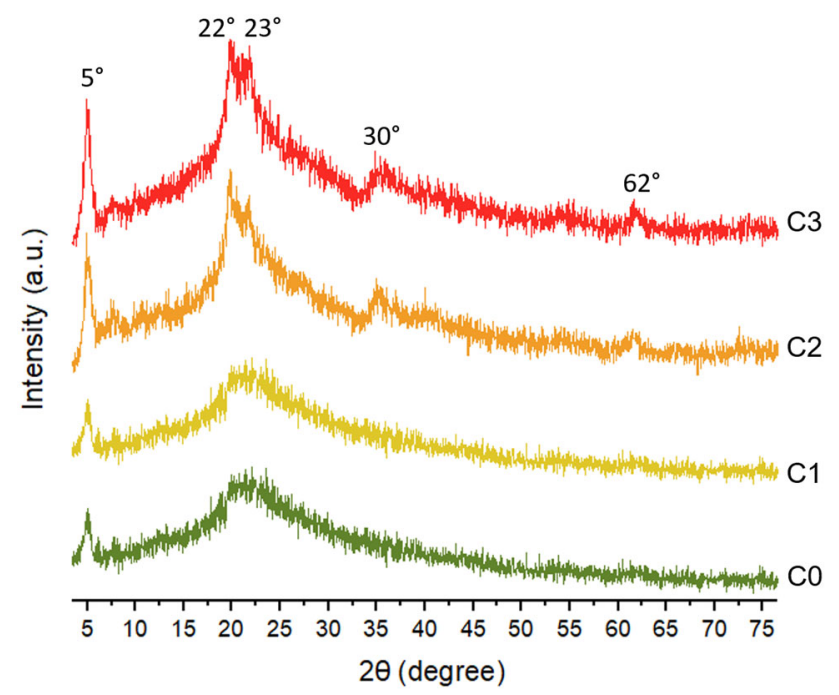

Figure 2. XRD patterns of the synthesized 3D scaffolds (C0-C3). water with 50, 60, 70, 80 and $90 \%$ of isopropanol (Sigma, USA) were used to rinse the cell-cultured plates. For each sample, three parallel replicates were analysed. The control sample is the empty wells without the synthesized 3D scaffold extracts.

The optical density (OD) values were recorded after removing the cover of cell-cultured plates at the wavelength of $570 \mathrm{~nm}$ by using an absorbance microplate reader (Bio-Tek, ELx-800, USA). The following equation used to calculate the cell viability:

$$
\text { Cell viability }(\%)=\left(\mathrm{OD}_{\text {sample }} / \mathrm{OD}_{\text {control }}\right) \times 100
$$

Finally, SEM (Tescan Vega 3 LMU with Bruker Quantax EDS, Czech Republic) images were used to investigate the adhesion of L929 cell culture to the synthesized 3D scaffolds.

\section{Results and discussion}

\subsection{Synthesized 3D scaffold characterization}

3.1a FTIR analysis: To study the possible formation of intermolecular bonds between the components of the synthesized 3D scaffolds and also to confirm the presence of nanoclay particles, the FTIR analysis was carried out (figure 1). Nanoclay particles showed hybrid bands in the region of 3125-3375 $\mathrm{cm}^{-1}$, a broad absorption bond. These peaks are assigned to $\mathrm{H}$ bonding and $\mathrm{OH}$ stretching. It was mainly because of the inherent structure of the nanoclay (hydroxyl group). A strong peak at $1050 \mathrm{~cm}^{-1}$ is associated with the $\mathrm{Si}-\mathrm{O}-\mathrm{Si}$ vibration, which exhibits the chemical composition
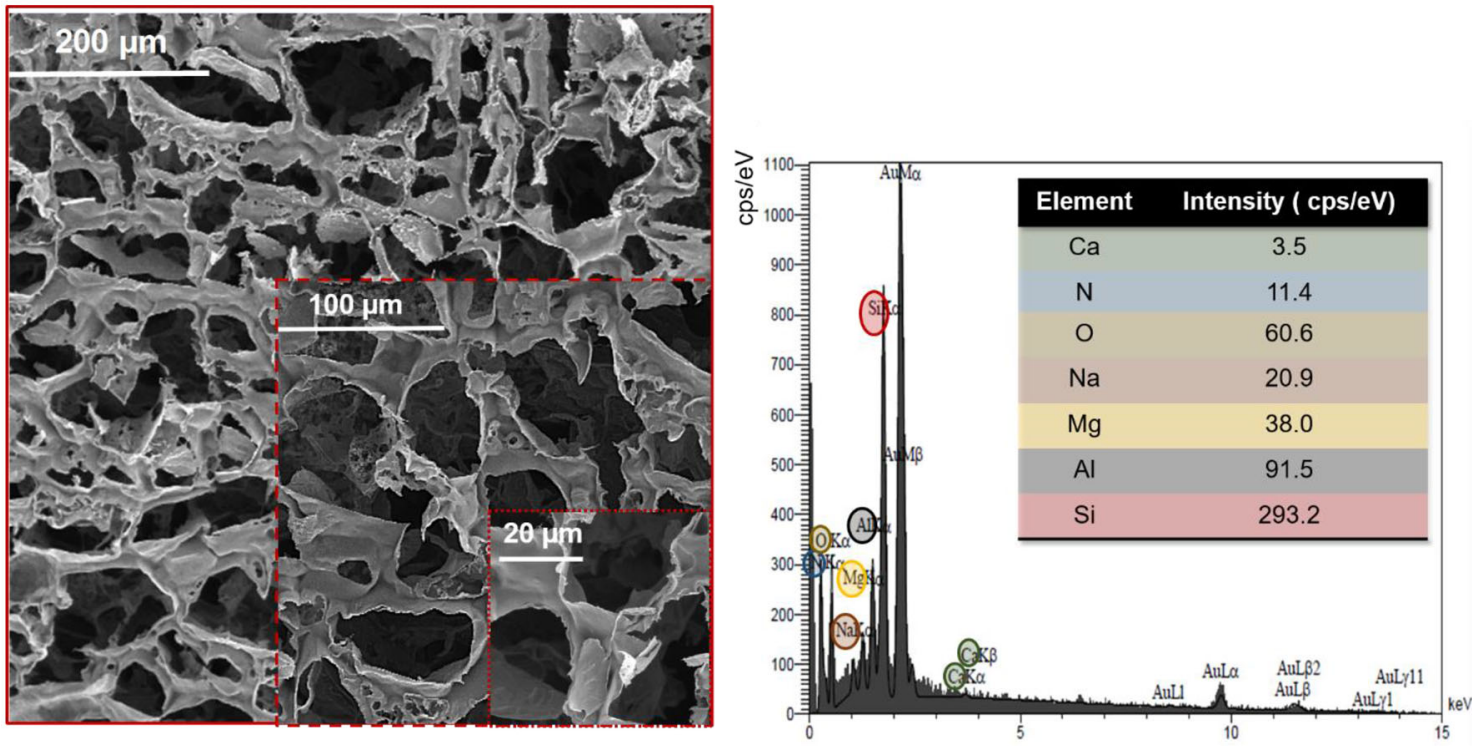

Figure 3. SEM images of the synthesized 3D scaffolds with $0.4 \mathrm{~g}$ nanoclay in three different scales $(200,100$ and $20 \mu \mathrm{m}$ ) from the horizontal direction. EDX point analysis for elemental composition of the C3 synthesized 3D scaffold sample. 
of the nanoclay. Two sets of peaks seen at approximately 2880 and $2854 \mathrm{~cm}^{-1}$ are related to compounds containing longlinear aliphatic chains. These two peaks were observed in all C0-C3 samples.

Characteristics bonding vibrations of $\mathrm{Si}-\mathrm{O}$ bonds were seen at $650 \mathrm{~cm}^{-1}$ [32]. The PVA $\mathrm{OH}$ and $\mathrm{CH}_{2}$ stretching vibration peaks are overlapped at $3125-3375 \mathrm{~cm}^{-1}$ with nanoclay related peaks. The intensity of these peaks increased with enhancing the amount of nanoclay. This can indicate that soluble parts of this synthesized 3D scaffolds contain $\mathrm{OH}$ and $\mathrm{NH}_{2}$ functional groups. The $\mathrm{OH}$ is from PVA and the $\mathrm{NH}_{2}$ is from CS or the PVA/CS hydrogen bonds with nanoclay [33]. The saccharide structure of CS led to peaks around 1015 and $1375 \mathrm{~cm}^{-1}$. Also the amino characteristic peak of the CS was observed around $1540 \mathrm{~cm}^{-1}[32,34,35]$.

3.1b XRD analysis: XRD patterns of the synthesized 3D scaffold are shown in figure 2. Typically, XRD is used to determine the structural characterization of an exfoliated nanocomposite [25]. Nanoclay shows a reflection peak at $2 \theta=5^{\circ}$. Bragg's law $(2 d \sin \theta=\lambda)$ was used to estimate the interlayer distance of the synthesized 3D scaffolds [22]. Hence, $d$-spacing of nanoclay equals to $2.0 \mathrm{~nm}$. The PVA showed the typical crystalline atactic peak at $2 \theta=22^{\circ}$ and a $d$-spacing of $1.2 \mathrm{~nm}$. CS showed a low intense peak at $2 \theta=5^{\circ}$ and $22^{\circ}$. It should be mentioned that because of the strong interaction between PVA and CS [27], the PVA/CS composite shows the pure PVA and CS related peaks with reduced intensity [36-38]. By addition and increasing the amount of nanoclay from the $\mathrm{C} 0$ to $\mathrm{C} 3$ sample, the peak intensity increased that means the enhancement in the crystalline area of the synthesized 3D scaffolds. In addition, C2 and C3 samples exhibit $2 \theta=23^{\circ}$ with a $d$-spacing of $1.4 \mathrm{~nm}, 2 \theta=30^{\circ}$ with a $d$-spacing of $1.8 \mathrm{~nm}$ and $2 \theta=62^{\circ}$ with a $d$-spacing of $3.0 \mathrm{~nm}$. These peaks confirmed the formation of interlayer nanoclay structure in the samples which led to improvement in the mechanical properties.

3.1c SEM and EDX analysis: Microstructure of the scaffolds, which are being used in tissue engineering applications, is one of their effective characteristics. Hence, SEM images of the synthesized 3D scaffold are presented in figure 3 that shows the irregularly interconnected porous microstructure. The rough texture of sub-micropores made the synthesized 3D scaffold a suitable candidate for cell culture application. The EDX spectroscopy analysis of the C3 sample displayed the main signal for nanoclay particles (i.e., silicone). The results of EDX analysis confirmed the presence of nanoclay particles in the walls of the inner pores of the synthesized 3D scaffolds.

\subsection{Synthesized 3D scaffolds' mechanical properties, porosity and pore size}

The macrostructure of the fabricated porous scaffolds to be used in bone tissue replacement application needs to be
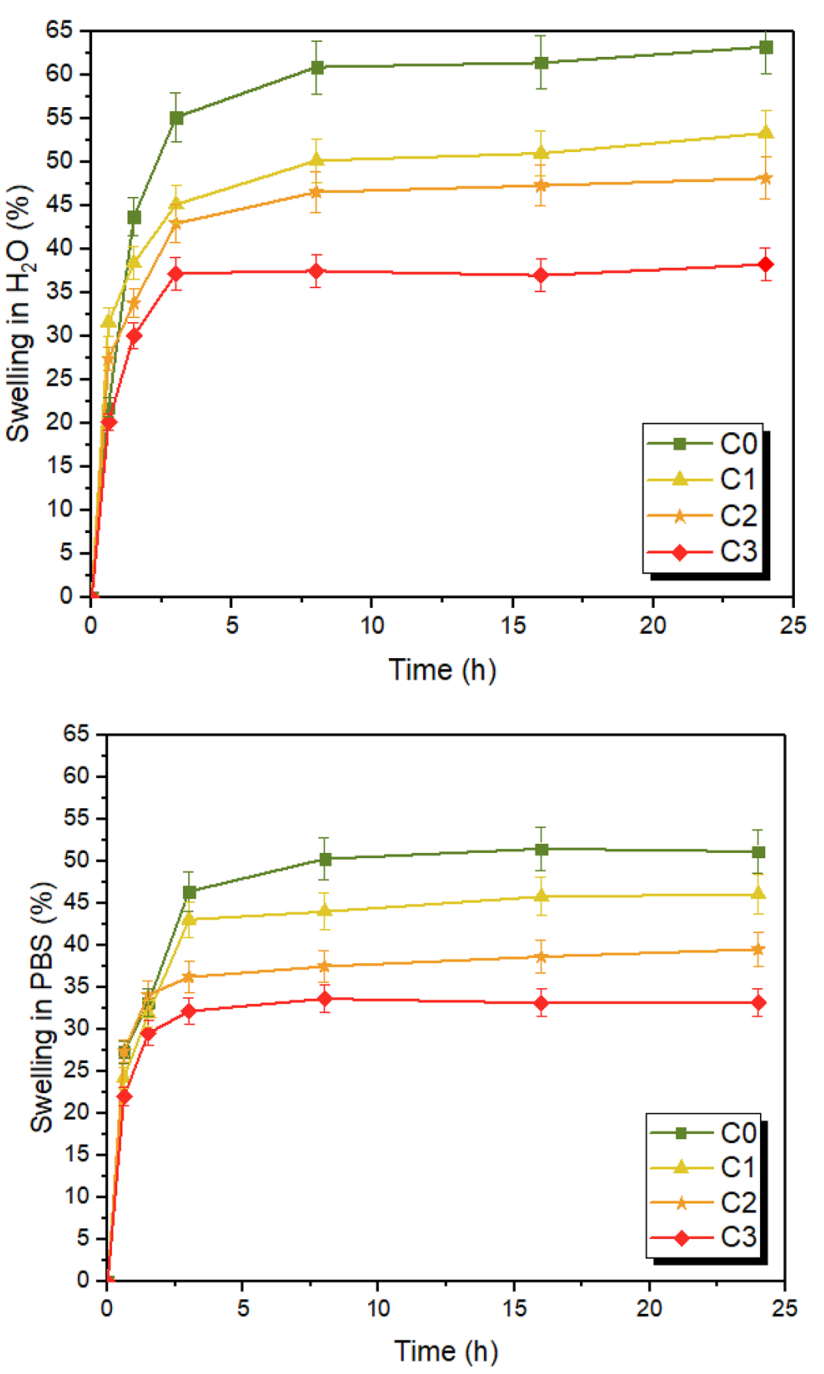

Figure 4. The swelling behaviour of the synthesized 3D scaffolds $(\mathrm{C} 0-\mathrm{C} 3)$ in distilled water and PBS solution. The experiments were carried out at $21^{\circ} \mathrm{C}$ for 3 days.

considered in terms of having sufficient mechanical properties [39]. Table 1 presents the elastic modulus and compressive strength of the synthesized 3D scaffolds. According to the results, increasing the amount of nanoclay particles in the structure of the synthesized $3 \mathrm{D}$ scaffolds from $0.0 \mathrm{~g}$ in the $\mathrm{C} 0$ sample to $0.4 \mathrm{~g}$ in the $\mathrm{C} 3$ sample enhanced the elastic modulus. A similar trend was seen for compressive strength of the samples. The highest compressive strength belongs to the C3 sample (i.e., $3.5 \pm 0.2 \mathrm{MPa}$ ) with the maximum amount of nanoclay particles. According to the literature, the elastic modulus and compressive strength of the C3 sample were in the range of reported for trabecular bone tissue [4,15].

In addition, the porosity and average pore size of the synthesized 3D scaffold are listed in table 1. The outcomes showed that the pore size of the sample decreased by increasing the amount of nanoclay particles from the $\mathrm{C} 0$ (i.e., 130-140 $\mu \mathrm{m})$ to C3 (95-115 $\mu \mathrm{m})$ samples. Otherwise, the porosity percentage of the samples increased from $\mathrm{C} 0$ (i.e., 

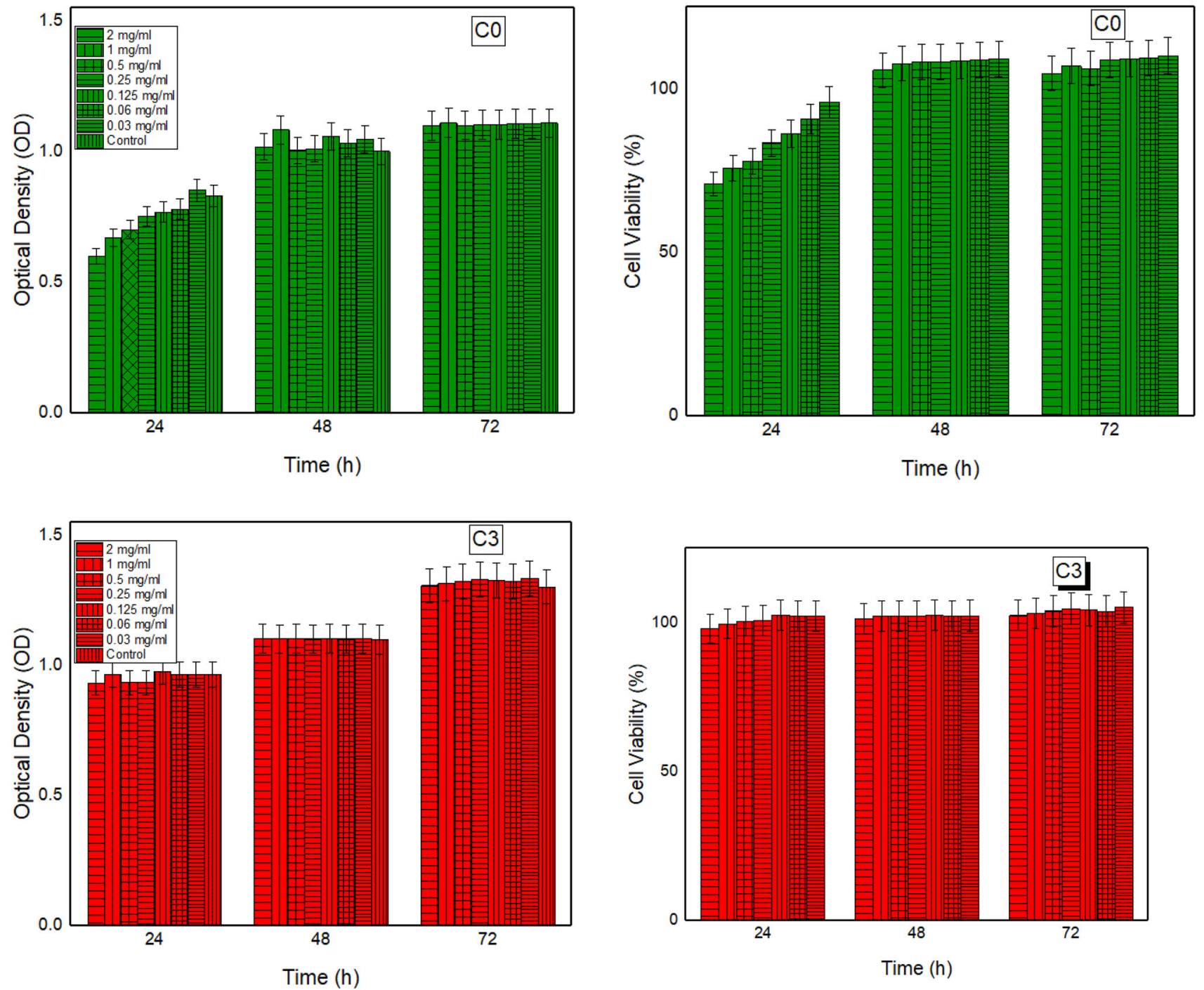

Figure 5. MTT assay of L929 cells for the different concentrations of the $\mathrm{C} 0$ and $\mathrm{C} 3$ synthesized $3 \mathrm{D}$ scaffold extracts ranging from 0.03 to $2.00 \mathrm{mg} \mathrm{ml}^{-1}$ after 24,48 and $72 \mathrm{~h}$. OD values were recorded at $570 \mathrm{~nm}$. The control sample is related to the wells containing L929 cells and the cell culture medium without scaffold extracts.

68-70) to C3 (i.e., 75-82). Increasing the porosity percentage combined with a reduction in the average pore size was a result of increasing the crystallinity of the synthesized 3D scaffolds which was confirmed by XRD patterns. Similar results have been reported by Manicini et al [24]. High porous scaffolds with desirable mechanical properties and pore morphology can be considered as proper candidates for bone tissue engineering applications.

\subsection{Synthesized 3D scaffold swelling behaviour}

The swelling percentage which represents the structural stability of the synthesized 3D scaffolds was determined by both distilled water and PBS solutions. The PBS solution matches the human body fluid in terms of osmolarity and ion concentrations. Upon immersing the sample in the solution, water molecules come into contact with the inner pores of the scaffolds and increased the osmotic pressure differences between the scaffold and the solution. Hence, the scaffold begun up-taking of the solution to reduce the pressure differences [40]. Immigration of water molecules into the scaffold structure led to observation of high swelling of the scaffold. Continuing the experiment and up-taking of more water molecules resulted in reduction of pressure differences. As the pressure differences decreased, the water molecule uptake reduced and also the swelling of the scaffold reduced consequently. When the pressure differences became very low, the system reached the equilibrium states and no more swelling of the scaffolds can be observed [41]. Figure 4 shows the result of swelling experiment in water and PBS. According to figure 4, by increasing the amount of nanoclay particles the swelling of samples reduced from $\mathrm{C} 0$ to $\mathrm{C} 3$. 

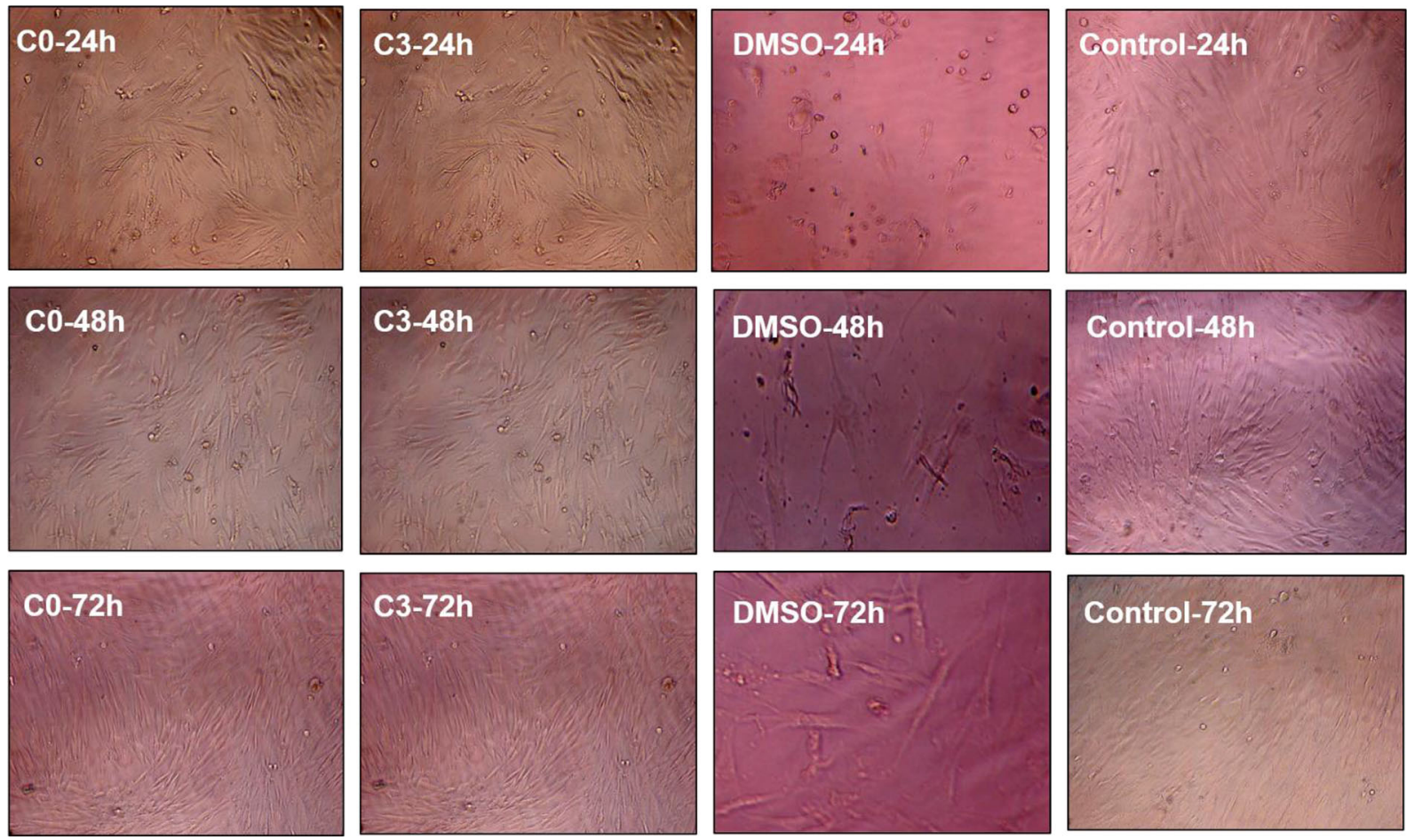

Figure 6. Optical images of the cell morphology using an optical microscope in the presence of the C0 and C3 synthesized 3D scaffold extracts with $0.03 \mathrm{mg} \mathrm{ml}^{-1}$ concentration in PBS solution after 24,48 and $72 \mathrm{~h}$.

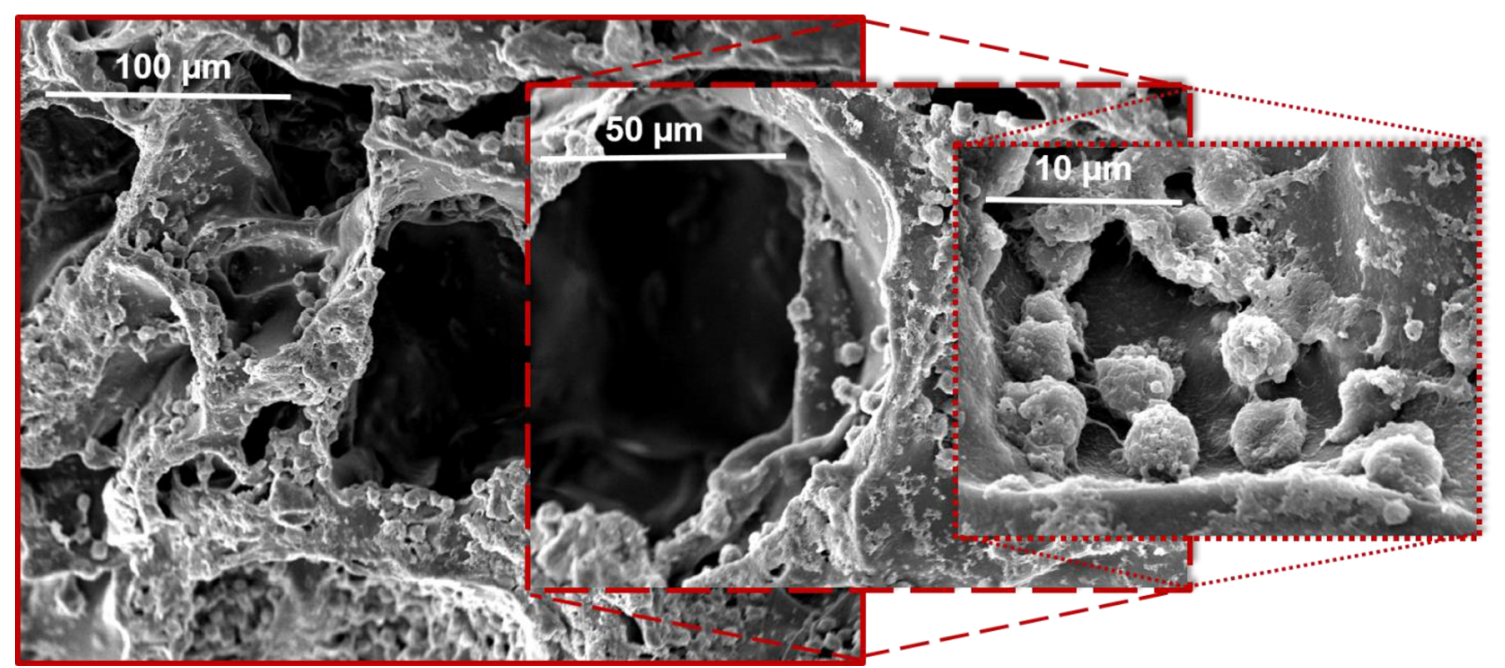

Figure 7. Scanning electron micrographs of L929 cells attached on the surface of the C3 synthesized 3D scaffold in three different scales $(100,50$ and $10 \mu \mathrm{m})$.

Furthermore, the maximum swelling percentage of $\mathrm{C} 0$ in distilled water was $63.28 \%$ which was greater than $51.19 \%$ in the PBS solution. The existence of nanoclay particles increased the crystalline regions in the synthesized 3D scaffolds as the XRD patterns (figure 2) confirmed. Therefore, the generation of ionic interaction between the PVA/CS/nanoclay composite with mono- and multi-valent ions in PBS solution resulted in lower swelling percentages in the PBS rather than water.

\subsection{Synthesized 3D scaffold cytotoxicity}

The synthesized 3D scaffold which will be chosen to be used for biomedical applications needs to be examined in terms of cytotoxicity. Original materials and byproduct of the scaffolds can cause cytotoxicity [42]. Seven different concentrations of $\mathrm{C} 0$ and $\mathrm{C} 3$ synthesized 3D scaffold extracts (ranging from 0.03 to $2.00 \mathrm{mg} \mathrm{ml}^{-1}$ ) were examined by evaluating the $\mathrm{L} 929$ cell viability using MTT assay. According to figure 5, both 
C0 and C3 samples exhibited sufficient cell viability in all different scaffold extract concentrations. Cell viability of the synthesized 3D scaffolds was higher than the cell viability of the control sample even after $24 \mathrm{~h}$ which indicated the high proliferation rate. Furthermore, the OD results revealed that both the $\mathrm{C} 0$ sample with no nanoclay particles and $\mathrm{C} 3$ with $0.4 \mathrm{~g}$ nanoclay particles were not toxic in all sample extract concentrations.

Figure 6 shows the optical image of the L929 cell cultured after 24,48 and $72 \mathrm{~h}$ on the $\mathrm{C} 0, \mathrm{C} 3$, dimethyl sulphoxide and the control samples. This figure exhibits that after $72 \mathrm{~h}$ of cell culturing, the L929 cells densely ordered and accumulated on each other. Thus, the synthesized 3D scaffold seems to be a suitable candidate for bone tissue engineering in terms of biocompatibility.

\subsection{Cell attachment study}

The SEM micrographs of L929 cells seeded on the surface of the C3 synthesized 3D scaffold are presented in figure 7. According to figure 7, the synthesized 3D scaffold possesses porous surface with proper pore size which allowed the L929 cells to attach to the surface of the scaffold sufficiently.

\section{Conclusions}

To be concluded, by utilizing the freeze-drying technique, the synthesized PVA/CS/nanoclay 3D scaffolds were successfully fabricated. Microstructural analysis including FTIR analysis, XRD patterns, SEM micrographs and EDX analysis showed that nanoclay particles were properly dispersed and incorporated into the PVA/CS composite matrix. Compared with the trabecular bone, the PVA/CS/nanoclay 3D scaffolds exhibited close mechanical properties, average pore size and porosity percentage. The samples showed a sufficient bio-stability especially in the PBS solution. L929 cells cultured in the PVA/CS/nanoclay 3D scaffolds confirmed the non-toxicity and biocompatibility of the samples. The SEM micrograph of the C3 sample demonstrated the suitable attachment of L929 cells on the inner pore walls of the synthesized 3D scaffold. Based on our experimental outcomes, the introduced novel 3D scaffold is capable of being considered as a promising candidate for bone tissue engineering applications.

\section{References}

[1] Braddock M, Houston P, Campbell C and Ashcroft P $2001 \mathrm{Am}$. Physiol. Soc. 1628

[2] Tsai S T, Hsu F Y and Chen P L 2008 Acta Biomater. 41332

[3] Uemura T, Dong J, Wang Y, Kojima H, Saito T, Iejima D et al 2003 Biomaterials 242277
[4] Meyer U, Joos U and Wiesmann H P 2004 Int. J. Oral Maxillofac. Surg. 33635

[5] Freyman T, Yannas I and Gibson L 2001 Prog. Mater. Sci. 46 273

[6] Zhou X H, Wei D X, Ye H M, Zhang X, Meng X and Zhou Q 2016 Mater. Sci. Eng. C 67326

[7] Fereshteh Z, Fathi M, Bagri A and Boccaccini A R 2016 Mater. Sci. Eng. C 68613

[8] Zhao W, Li J, Jin K, Liu W, Qiu X and Li C 2016 Mater. Sci. Eng. C 591181

[9] Saravanan S, Sameera D K, Moorthi A and Selvamurugan N 2013 Int. J. Biol. Macromol. 62431

[10] de Araújo Júnior A M, Braido G, Saska S, Barud H S, Franchi L P, Assunção M N et al 2016 Carbohydr. Polym. 136 892

[11] Kruppke B, Farack J, Wagner A S, Beckmann S, Heinemann C, Glenske K et al 2016 Acta Biomater. 32275

[12] Pon-On W, Suntornsaratoon P, Charoenphandhu N, Thongbunchoo J, Krishnamra N and Tang I M 2016 Mater. Sci. Eng. C 62183

[13] Beladi F, Saber-Samandari S and Saber-Samandari S 2017 Mater. Sci. Eng. C 75385

[14] Langer R and Vacanti J P 1993 Sciene 26092

[15] Ma P X, Zhang R, Xiao G and Franceschi R 2001 J. Biomed. Mater. Res. 54284

[16] Peter M, Binulal N S, Nair S V, Selvamurugan N, Tamura H and Jayakumar R 2010 Chem. Eng. J. 158353

[17] Cerchiara T, Luppi B and Bigucci F 2003 Eur. J. Pharm. Biopharm. $\mathbf{5 6} 401$

[18] Hassan C M and Ward J H 2000 Polymer 416729

[19] Hassan C M and Peppas N A 2000 Macromolecules 33 2472

[20] Sin L T, Rahman W A, Rahmat A R and Mokhtar M 2011 Carbohydr. Polym. 83303

[21] Kim S J, Lee C K and Lee Y M 2003 React. Funct. Polym. 55 291

[22] Părpăriţăa E, Cheaburua C N, Pațachiab S F and Vasilea C 2014 Acta Chem. Iasi 2275

[23] Jayakumar R, Prabaharan M, Nair S V and Tamura H 2010 Biotechnol. Adv. 28142

[24] Mirzaei E, Faridi-Majidi R, Shokrgozar M A and Asghari Paskiabi F 2014 Nanomed. J. 1137

[25] Mahdavi H, Mirzadeh H, Zohuriaan-Mehr M J and Talebnezhad F 2013 J. Am. Sci. 9203

[26] Abd-Khorsand S, Saber-Samandarib S and Saber-Samandaric S 2017 Int. J. Biol. Macromol. 10151

[27] Karamian E, Kalantar Motamedi M R, Khandan A, Soltani P and Maghsoudi S 2014 Prog. Nat. Sci. 24150

[28] Kim H W, Knowles J C and Kim H E 2004 J. Biomed. Mater. Res. B 70240

[29] Saber-Samandari S and Gross K A 2009 Acta Biomater. 5 2206

[30] Saber-Samandari S, Saber-Samandari S, Ghonjizade-Samani F, Aghazadeh J and Sadeghi A 2016 Ceram. Int. 4211055

[31] Saber-Samandari S, Saber-Samandari S, Kiyazar S, Aghazadeh J and Sadeghi A 2016 Int. J. Biol. Macromol. 86434

[32] Guan Y L and Yao K D 1996 J. Appl. Polym. Sci. 612325

[33] Ray S S, Okamoto K and Okamoto M 2003 Macromolecules 362355

[34] Azizi H, Morshedian J, Barikani M and Wagner M 2010 Express Polym. Lett. 4252 
[35] Koosha M, Mirzadeh H, Shokrgozar M A and Farokhi M 2015 RSC Adv. 510479

[36] Yang J M, Su W Y, Leu T L and Yang M C 2004 J. Membr. Sci. 23639

[37] Zheng H, Du Y, Yu J, Huang R and Zhang L $2001 \mathrm{~J}$. Appl. Polym. Sci. 802558

[38] Kabiri Bamoradian K, Mirzadeh H and Zohuriaan-Mehr M J 2007 Iran Polym. J. 16147
[39] Sabree I, Gough J E and Derby B 2015 Ceram. Int. 41 8425

[40] Chen P Y and McKittrick J 2011 J. Mech. Behav. Biomed. Mater. 4961

[41] Saber-Samandari S, Gulcan H O, Saber-Samandari S and Gazi M 2014 Water Air Soil Pollut. 2252177

[42] Lee S, Porter M, Wasko S, Lau G, Chen P Y, Novitskaya E E et al 2012 Mater. Res. Soc. Symp. Proc. 1418177 